\title{
Diversidade e Computação a Partir de uma Ação de Extensão Participativa e Coletiva
}

\author{
Leander Cordeiro de Oliveira ${ }^{1}$, Marília Abrahão Amaral ${ }^{2}$ \\ ${ }^{1}$ Departamento de Informática (DIN) - Universidade Estadual de Maringa (UEM) \\ Maringá - PR - Brasil \\ ${ }^{2}$ Programa de Pós-graduação em Tecnologia e Sociedade (PPGTE) - Universidade \\ Tecnológica Federal do Paraná (UTFPR) \\ Curitiba - PR - Brasil \\ leanderdeoliveira@gmail.com, mariliaa@utfpr.edu.br
}

\begin{abstract}
This article aims to present and analyze a participatory and collective extension action developed to discuss agendas of diverse and dissident groups through art and technology. In this way, questions linked to the LGBTTQIA+ movements, the normativities in the area of computing, the spaces and creation labs (Hacker and Maker) and the construction of Computational Thinking are articulated as a way to seek for a deconstruction in the area and in society.
\end{abstract}

Resumo. Este artigo tem como objetivo apresentar e analisar uma ação de extensão participativa e coletiva desenvolvida com o intuito de discutir pautas de grupos diversos e dissidentes por meio da arte e da tecnologia. Articulamse, dessa forma, assuntos ligados aos movimentos LGBTTQIA+, as normatividades da área da computação, os espaços e labs de criação (Hacker e Maker) e a construção do Pensamento Computacional como forma de buscar por uma desconstrução na área e na sociedade.

\section{Introdução}

Há alguns anos cresce a crítica sobre a maneira como a computação se fecha em círculos que incluem pessoas de um perfil similar. Vem sendo apontada uma dominação masculina, com certas configurações econômicas, sociais e culturais específicas, apresentando pouca diversidade, o que acaba por ser um reflexo para os ambientes e tecnologias que a própria computação constrói. Winner (1986), autor no campo de Ciência, Tecnologia e Sociedade (CTS), argumenta que artefatos tecnológicos carregam valores sociais, culturais e políticos, ou seja, são reflexos do contexto no qual foram desenvolvidos. Tal discussão aborda a tecnologia, e por consequência a computação, a partir de seus aspectos culturais e sociais, compreendendo que as tecnologias computacionais já se encontram espalhadas para as mais diversas esferas da vida das pessoas na contemporaneidade (Bødker, 2015). Cresce, assim, o seu envolvimento nas experiências e processos socioculturais desdobrados e relacionados com a tecnologia.

A partir deste recorte, a discussão de gênero cresce, trazendo diferentes perspectivas das Ciências Sociais, do campo CTS e dos Estudos de Gênero e Sexualidade para compreender os fenômenos ligados à estas construções para as áreas de computação, tecnologia e interação. Estudos como os de Bardzell e Bardzell (2015), Breslin e Wadhwa (2014, 2015), Light (2011), Merkle (2010), Marshall e Rode (2018), 
Rode (2011) compartilham de conceitos das teorias pós-identitárias, buscando discutir gênero para além das binaridades e dos estereótipos da masculinidade e feminilidade, levantando a questão de que este tipo de perspectiva pode ser problemática, visto que reiteram formas normativas de ser e de possibilidades ligadas às construções de gênero, deixando de lado a interseccionalidade de marcadores sociais e culturais que perpassam a vida em sociedade.

Light (2011) dá um passo em uma direção um pouco diferente ao buscar especificamente na Teoria Queer a fundamentação para a sua discussão, compreendendo as potencialidades desta teoria como maneira de questionar situações de invisibilização, opressão, precariedade e abjeção que dizem respeito às relações entre pessoas e tecnologias computacionais.

Com este delineamento é possível desvelar a crescente denuncia de que a computação é uma área que tem apresentado dificuldade em envolver pessoas diversas, sendo dominada por homens com características sociais, culturais, econômicas e políticas muito específicas. Estudos como Castelini (2018), Amaral et al. (2017), Silva (2016a, 2016b) apresentam parte dessa problemática, discutindo questões de mulheres na área. As discussões dessa pesquisa, por sua vez, buscam endereçar também questões envolvidas em outros espectros, como o da sexualidade, por exemplo, dando caminho para uma reflexão que considera a interseccionalidade e a Teoria Queer. Como base para pensar as questões de pessoas LGBTTQIA+, alguns estudos que buscam discutir a relação desses grupos com a computação, tecnologia e demais áreas STEM foram resgatados (Stout e Wright, 2016; Trenshaw et al., 2013; Cech e Waidzunas, 2011; Bilimoria e Stewart, 2009; Grogan, 2014; ABGLT, 2016), trazendo dados sobre invisibilizações, estigmatizações, exclusões e até mesmo violências que estas pessoas e grupos sociais sofrem em diversos espectros de suas formações e atuações profissionais.

Estes estudos trouxeram informações importantes para o desenvolvimento deste artigo, fruto da pesquisa de Oliveira (2020) que buscou problematizar as construções normativas ligadas a computação e a tecnologia por meio de uma ação de extensão participativa e coletiva. Estiveram diretamente envolvidos grupos sociais e pessoas que não vivem e existem a partir de construções normativas de gênero e/ou sexualidade. $O$ trabalho de Ames et al. (2018) pontua a relevância em compreender espaços Hacker e Maker como possíveis articuladores de pautas que, passando pela política e pela ética, tocam as vidas de pessoas que estão à margem. Alguns pontos importantes que se alinham às discussões da ética Hacker e Maker são a perspectiva da experimentação, do fazer artístico, da exploração, da gambiarra e da bricolagem (Ames et al., 2018).

As discussões de Wing (2006) indicam uma disseminação dos conceitos, práticas, reflexões e teorias da área de computação, algo que traz a importância de se trabalhar o Pensamento Computacional como forma de democratizar estas construções. Blikstein (2008) aponta que compreender as potencialidades que a formação em computação traz para as outras áreas da vida que estão além da formação acadêmica ou do mundo do trabalho é tarefa necessária em nosso tempo. Um envolvimento de pessoas historicamente excluídas precisa ser parte deste processo. A busca por uma construção de diversidade para as áreas ligadas a computação é algo imprescindível quando discute-se a democratização e o acesso destes saberes na sociedade e na cultura.

Compreendendo que as discussões da Teoria Queer apontam para uma forte perspectiva de ação para a desconstrução neste âmbito (Light, 2011), alinham-se à 
potencialidade dos laboratórios e espaços de criação e experimentação, ligados às perspectivas Hacker e Maker e aos estudos sobre Pensamento Computacional como possíveis fomentadores dessas discussões. Dessa forma o objetivo deste artigo é relatar e analisar a ação de extensão denominada Performatividade - Arte • Tecnologia (PAT) como forma de trabalhar as questões de grupos dissidentes por meio de experimentações e interações artísticas e tecnológicas. É importante destacar que parte central desta pesquisa traz a perspectiva de ação e envolvimento direto das pessoas na construção de uma discussão sobre computação e tecnologia interligada a suas existências e vivências enquanto pessoas que não se enquadram nas hegemonias sociais e culturais no que diz respeito ao gênero e/ou a sexualidade.

\section{Abordagem Metodológica}

A presente pesquisa se desenhou por um olhar que partiu dos estudos de gênero, sexualidade e identidade, em especial a Teoria Queer, para pensar sobre computação e tecnologia, em perspectiva de questionamento e envolvimento da diversidade na área. A Teoria Queer parte de uma perspetiva de desestabilização (Miskolci, 2014), o que exigiu uma construção de pesquisa aprofundando engajamento e responsabilidade ética. Por isso a pesquisa aconteceu com um processo de imersão do pesquisador com as comunidades, trazendo características de pesquisa participante (Brandão e Borges, 2007). A transformação social foi um motivador, alinhada a compromissos éticos, sociais, políticos e ideológicos da comunidade com a qual houve interação e com a qual se construiu a pesquisa a partir de suas realidades concretas (Brandão e Borges, 2007).

Assim, articulou-se a construção da ação de extensão, PAT, de forma dialógica e em conjunto às pessoas envolvidas. Essa perspectiva buscou reafirmar a crítica de Paulo Freire (2015) a extensão universitária, levando a uma ação de extensão e pesquisa com responsabilidade ética, dialógica e conjunta com a comunidade, entendendo que todas as pessoas, grupos e culturas são fontes originais de saberes, fazeres e quereres. Temos, assim, como foco principal a articulação do problema tratado e seus desdobramentos a partir do olhar do grupo que esteve envolvido nas ações, com as produções sendo a fonte para uma análise a partir das categorias apontadas pela fundamentação teórica.

A pesquisa é compreendida como qualitativa, pois aborda questões subjetivas. E possui natureza aplicada, uma vez que estão articuladas teorias a partir de realidades. $\mathrm{O}$ objetivo, por sua vez, é entendido como explicativo, uma vez que a abordagem é qualitativa justamente como maneira de estudar uma realidade e os significados que estão no entorno do problema tratado (Marconi e Lakatos, 2003). Os caminhos da pesquisa foram registrados em um diário de pesquisa como o principal recurso para a documentação e recuperação, visando a reprodutibilidade do processo de pesquisa, recurso defendido por Mills (2009). Por meio destes registros manteve-se o rigor metodológico, ao mesmo tempo em que foi possível estimular reflexões, criatividade e criticidade sobre problema e objetivo da pesquisa. As obras, resultado da ação, também foram maneira de analisar e compreender as articulações e intenções das participantes.

A partir da natureza da pesquisa definiram-se as seguintes etapas (Bardin, 2011; Francisco et al., 2021): (1) pesquisa e leitura de artigos, livros, teses alinhadas às temáticas da pesquisa como forma de elencar caminhos de ação; (2) contato com o público a partir de eventos acadêmicos, fóruns de discussão, eventos culturais; (3) articulação e desenvolvimento da ação de extensão participativa e coletiva; (4) pré- 
análise, codificação dos documentos gerados nas observações participantes para definição das categorias de análise e posterior tratamento dos resultados (5) reflexão e análise sobre as produções do grupo.

\subsection{A Oficina Performatividade • Arte • Tecnologia (PAT)}

A ação de extensão participativa e coletiva Performatividade $\cdot$ Arte $\cdot$ Tecnologia (PAT) foi desenvolvida a partir de demandas de estudantes do curso de Licenciatura em Artes Visuais da Universidade Estadual do Paraná (UNESPAR) em conjunto com membros do Grupo Xuê e do Grupo PET-CoCE , ligados a Universidade Tecnológica Federal do Paraná (UTFPR).

O grupo se organizou a partir de contatos dos envolvidos e da divulgação das ideias da oficina em redes sociais. Foram produzidas um série de oficinas, mesas de debate e oficinas de produção. A prática começou a ser organizada tendo como objetivo a articulação de pessoas da comunidade com interesse em debates e produções em arte e tecnologia, discutindo questões das dissidências em um espaço de prática e experimentação Hacker e Maker. Desta forma, seria possível articular fazeres e discussões decorrentes, deslocando a computação para um espaço de experimentação, extrapolando o foco em artefatos e sistemas, mas ainda compreendo-os como apoio

A metodologia articulada para os encontros previa flexibilidade em temáticas e organização, sendo reconstruída no decorrer das semanas a fim de valorizar a coletivividade, horizontalidade e dialogicidade. A partir disso, ocorreram 16 encontros semanais com duração de 2 horas que versaram sobre: (1) apresentações iniciais; (2) história da arte: do renascentismo a arte contemporânea; (3) Arte contemporânea e arte performática; (4) Arte e tecnologia; (5) Glitch Art: Prática; (6) Mostra Queermuseu: cartografias da diferença na arte brasileira; (7) Gênero e Sexualidade; (8) e (9) Discussão e concepção das poéticas; (10), (11), (12) e (13) Produção dos projetos; (14) e (15) Organização da socialização; (16) Mesa de Debates PAT.

Ainda que houvessem momentos específicos, todos os assuntos estiveram presentes transversalmente nos encontros. Assim seria possível pensar a computação e a tecnologia e suas relações em conjunto as pessoas presentes, em discussões originadas em pautas dos envolvidos e na forma como articulam suas vidas por meio das tecnologias e da arte. Inicialmente 26 pessoas se interessaram em fazer parte, sendo que algumas começaram a frequentar os encontros, mas não caminharam até o final das ações. Todas assinaram Termo de Consentimento Livre e Esclarecido e podiam abrir mão de participar a qualquer momento. Ao fim, se consolidou um grupo de dez pessoas com diferentes backgrounds e interesses.

\section{Abordagem Teórica}

A presente pesquisa apresenta fundamentação interdisciplinar, busca na Teoria Queer as bases para a discussão sobre as questões da diversidade no que diz respeito às construções de gênero e sexualidade. Autoras como Butler $(2007,2009,2017)$ e Preciado $(2011,2014)$ trazem importantes discussões que dão base a perspectiva desconstrutiva da Teoria Queer no que diz respeito às binaridades de gênero e a heteronormatividade, compreendendo as relações de poder que influenciam nas normatizações de gênero nas mais diversas esferas de nossa sociedade. Spargo (2006), Louro (2016) e Sierra (2017) também são importantes autoras que pensam as 
perspectivas das identidades a partir da teorização Queer, apontando que ela traz em suas discussões um fator de atitude, especificamente na desestabilização das normas de gênero e sexualidade. Vale pontuar que o Queer entende que essas normatizações são construídas a partir da chamada heteronormatividade e dos binarismos de gênero (masculinidade versus feminilidade, cisgeneridade versus transgeneridade, por exemplo) (Sierra, 2017), e que essas estruturas precisam ser questionadas e ultrapassadas.

Acerca dos labs e espaços de criação, autores como Blikstein (2016), Himanen (2003), Evangelista (2014), Fonseca (2014), Silva (2017), Levy (1994) trazem discussões sobre as potencialidades de espaços deste tipo, alinhados às perspectivas Hacker e Maker. Blikstein (2016), inclusive, aponta estas potencialidades especificamente pensando em espaços educativos. É importante pontuar que as circunstâncias que deram base para este tipo de espaço foram comunidades de inovação que se estabeleceram por décadas a partir da cultura do "hacking", surgindo o primeiro FabLabs como "essencialmente laboratórios hackers de alta tecnologia" (Blikstein, 2016). Por sua vez, Ames et al. (2018) pontua a importância de entender espaços Hacker e Maker como possíveis articuladores de pautas que, passando pela política e pela ética, envolvem questões e situações que tocam as vidas de pessoas que estão à margem. Alguns pontos importantes que se alinham às discussões da ética Hacker e Maker são a perspectiva da experimentação, do fazer artístico, da exploração, da gambiarra e da bricolagem. Marshall e Rode (2018) conectam os estudos de gênero aos movimentos Hacker e Maker, apontando que nestes espaços, os fazeres concretos passam pela corporalidade, ou seja, pela construção das pessoas e suas identidades. Estas discussões trazem apontamentos pertinentes para a discussão sobre processos de democratização da computação e da tecnologia e, consequentemente, para a construção de Pensamento Computacional.

Algumas iniciativas recentes que abordam tecnologia em perspectivas educacionais dizem respeito a como desenvolver os saberes aprendidos por profissionais de computação para outras pessoas que estão fora desta área de formação (Wing, 2006; Nardelli, 2019). Conforme discute Wing (2006), a disseminação do pensamento computacional (PC), com o passar dos anos, passa a ser um dos caminhos pelo qual a atuação na área de computação se pauta. Entende-se que os conceitos, práticas, reflexões, teorias da área se disseminam pelo mundo com certa rapidez e que dominar estas construções passa a ser uma novo desafio para os processos educativos.

Wing (2006) traz um conjunto de seis características do que entende como PC: (i) a compreensão de que computação não é somente programação, mas sim um conjunto de múltiplas habilidades que levam a diferentes níveis de abstração; (ii) PC é uma habilidade fundamental e não uma rotina mecânica, uma vez que todas as pessoas passarão a precisar de domínio e não apenas uma dominação mecânica nesta habilidade; (iii) o PC diz respeito a maneira como as pessoas resolvem problemas e não sobre como os computadores "pensam", desta forma, trata da habilidade humana em se apropriar dos saberes e fazeres desenvolvidos a partir da área de computação; (iv) permite combinar pensamento matemático e de engenharia, uma vez que a computação objetiva construir sistemas que lidam com questões do mundo real, como na engenharia, e tem sua base de fundamentação na matemática; (v) o PC tem que ser trabalhado não apenas com o software e hardware que são desenvolvidos pela computação, mas também a partir dos conceitos usados para abordar e resolver problemas e situações do cotidiano e 
na comunicação e interação entre as pessoas; e (vi) PC tem que ser para todo mundo, em todos os lugares, integrado a vida das pessoas.

André (2018) desenvolve uma reflexão sobre o PC enquanto estratégia para a construção da cidadania, uma vez que as competências relacionadas ao PC fazem parte da compreensão do mundo contemporâneo. Isso se dá, pois a capacidade de analisar e investigar situações para construir decisões relacionadas a natureza, sociedade, ciência e tecnologia pode ser desenvolvida a partir do pensamento computacional. Da mesma forma como a construção de capacidades de comunicação e expressão e da relação com as diferenças e a alteridade. Esses valores também estão presentes nas comunidades Hacker e Maker, relacionada aos grupos e comunidades conforme discute Levy (1994), em especial no que diz respeito à abertura e acesso a informação.

Como forma de compreender a potencialidade da conexão da base teórica adotada por esta pesquisa, é possível resgatar o que discutem Brennan e Resnick (2012) sobre as perspectivas computacionais em PC, ao defenderem que é possível: expressar, compreendendo que a computação é meio de criação; conectar, uma vez que a atividade criativa e de aprendizagem é meio para construir relações, não apenas entre pessoas, mas também entre projetos e perspectivas, gerando colaboração, envolvimento e engajamento; questionar, sendo que esta perspectiva está fortemente ligada ao empoderamento, uma vez que domínio sobre a tecnologia é caminho para questionamento através do design de novas tecnologias.

Outra perspectiva potente para pensar essa relação é a discussão que a autora Light (2011) constrói ao conectar o design de tecnologias com a Teoria Queer a partir do que ela chama de design para a obliquidade, ou seja, um design para o enfrentamento e questionamento. Para isso, as categorias apontadas pela autora são: esquecer, obscurecer, trapacear e iludir. Esquecer (1) liga-se a ideia de que é preciso poder esquecer coisas para que seja possível manter a capacidade de perdão e reconstrução, algo que a ampliação do armazenamento e as redes sociais tornaram mais difíceis. É forma de permitir que outros futuros sejam possíveis, algo que toca as identidades de pessoas dissidentes uma vez que influencia neste processo de quebra de normatividade. Obscurecer (2) traz para a discussão o fato de que as pessoas precisam ter controle sobre o que mostram e/ou escondem ao usarem artefatos tecnológicos, algo que também influencia na construção identitária por meio da performance e da performatividade (Butler, 2007, 2009, 2017). Trapacear (3) fala sobre burlar sistemas de regras nos ambientes dos jogos e estender esta ação para outros espaços. A possibilidade de trapacear mostra que os jogos e sistemas são construídos a partir de regras e normas, mas que sempre haverão falhas e outros caminhos que podem ser explorados e seguidos. Abre-se espaço para gambiarras, bricolagem e experimentação como formas de fomentar possibilidades. Por fim, a ideia de Iludir (4) defende que é preciso desvirtuar os significados de termos e entidades em ontologias e na Web Semântica para lutar contra cristalização de significados e por ampliações nos fluxos de saber e ser. A forma como os dados são tratados pelas ferramentas pode reforçar normatividades e deve ser um exercício constante manipular e iludir estes significados.

Ao relacionar essas categorias com as discussões sobre PC e os movimentos hacker e maker, sobressaem as possibilidades para pensar uma computação a partir da diversidade e também de um processo desconstrutivo da própria área. 


\section{Resultados e Discussões}

$\mathrm{Na}$ sequencia são trazidas três obras desenvolvidas durante a oficina com respectivas análises. Ao todo, foram desenvolvidas sete produções, descritas na Tabela 1. O catálogo completo e as discussões aprofundadas de podem ser lidos em Oliveira (2020).

Tabela 1. Produções e artistas.

\begin{tabular}{|c|c|c|c|}
\hline Obra & Artistas & Proposta & Suporte \\
\hline Lar Doce Lar & FM & $\begin{array}{l}\text { Discutir os espaço da casa LGBTQI+, desconstrução da casa, os estereótipos } \\
\text { de gênero e sexualidade; }\end{array}$ & $\begin{array}{l}\text { Modelagem } \\
\text { tridimensional }\end{array}$ \\
\hline Controle Tóxico & $\begin{array}{l}\text { LO; } \\
\text { LR }\end{array}$ & $\begin{array}{l}\text { Discudir preconceitos nos jogos e videogames e os discursos de ódio } \\
\text { direcionados a públicos dissidentes em fóruns utilizados por esses públicos }\end{array}$ & $\begin{array}{l}\text { Instalação; impressão } \\
\text { tridimensional }\end{array}$ \\
\hline @oquetemarca & $\begin{array}{l}\text { FHA; } \\
\text { LO }\end{array}$ & $\begin{array}{l}\text { Discutir corpo e corporalidade, padrões e normatividades corporais, cirurgias } \\
\text { plásticas, modificações corporais, cicatrizes e marcas em uma perspectiva de } \\
\text { aceitação e celebração }\end{array}$ & $\begin{array}{l}\text { Instalação; dispositivos } \\
\text { móveis; redes sociais }\end{array}$ \\
\hline Sem Título & UV & $\begin{array}{l}\text { Discutir prostituição, transexualidades, violências, corpo e corporalidades em } \\
\text { relação a espaços público/privado, tecnologias de gênero e tecnologias em } \\
\text { esquecimento. Mais detalhes podem ser lidos em Oliveira e Costa (2021) }\end{array}$ & $\begin{array}{l}\text { Videoperformance; } \\
\text { instalação; edição de } \\
\text { áudio e vídeo }\end{array}$ \\
\hline $\begin{array}{l}\text { Games Pra } \\
\text { Quem? }\end{array}$ & LR & $\begin{array}{l}\text { Discutir videogames, a indústria de jogos, o processo de estranhamento de } \\
\text { personagens, a inversão de estereótipos; }\end{array}$ & $\begin{array}{l}\text { Instalação; manipulação } \\
\text { de imagens }\end{array}$ \\
\hline Sem Titulo & $\begin{array}{l}\text { BRR; } \\
\text { BR }\end{array}$ & $\begin{array}{l}\text { Discutir corpo e corporalidade suscitando a reflexão quanto ao preconceito } \\
\text { sofrido por pessoas fora do padrão cis-heteronormativo e eurocêntrico }\end{array}$ & $\begin{array}{l}\text { Instalação; raios-x; } \\
\text { sensoriamento }\end{array}$ \\
\hline PAT.doc & $\begin{array}{l}\text { SL; } \\
\text { BG }\end{array}$ & $\begin{array}{l}\text { Construir um vídeo documentário sobre os encontros da oficina-coletivo, } \\
\text { visando documentação e processo de curadoria. }\end{array}$ & $\begin{array}{l}\text { Videoarte; captação e } \\
\text { edição de áudio e vídeo }\end{array}$ \\
\hline
\end{tabular}

\subsection{Lar Doce Lar - FM}

A obra tem como pressuposto discutir a relação que existe entre os espaços da casa e grupos LGBTTQIA+ por meio de questões como os estereótipos, violências e espaços de precariedade e abjeção ligados a estes grupos (Figura 1). A obra remete à casa enquanto um espaço de construção de identidades e de tecnologias, no sentido de que estes espaços concretizam valores, desejos, anseios, traumas e medos das pessoas que ali vivem, próximo as discussões de Marshall e Rode (2018). Vem à tona a problematização da heteronormatividade e dos relacionamentos não heterossexuais em uma sociedade que tem dificuldade em lidar com formas de família não hegemônicas.
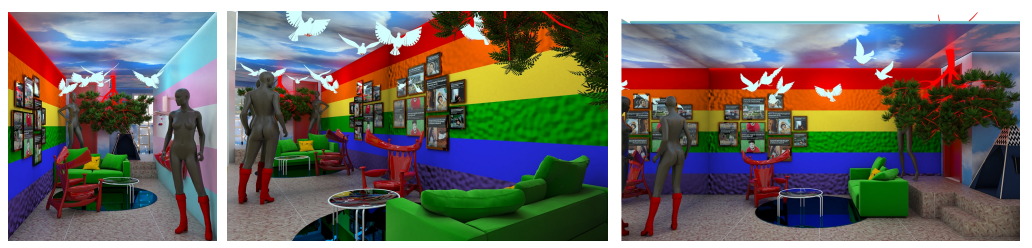

Figura 1: Imagens da Obra Lar Doce Lar de FM

Fontes: Composição dos autores (Oliveira, 2020) / Obra de FM

As categorias de Light (2011) articuladas na obra são obscurecer, uma vez que é trazida a construção de identidades em um processo que remete-se às escolhas de mostrar ou esconder elementos. Também trapacear e iludir, pois estão relacionadas principalmente com o fato de o artista se aproveitar das brechas que encontra em sua relação com tecnologias de trabalho para construir uma poética, aproveitando-se delas, discutindo também estereótipos para que então possa tentar subvertê-los na produção. Neste caso, ao adicionar ao ambiente elementos que parecem exageradamente fora de contexto ou alegóricos, FM, que é designer de interiores, cria deslocamentos de significado sobre determinadas convenções quando se pensa nos espaços da casa e como estas convenções advém de uma sociedade heteronormativa.

FM desenvolveu sua obra utilizando softwares de modelagem tridimensional, no caso o Sketchup, que apresenta diferentes tipos de licença, dentre as quais há uma aberta. 
As ideias sobre as licenças de software e de informação, discutidas pelas comunidades Hacker e Maker (Levy, 1994) são tensionadas neste ponto. Ainda que seja apenas uma licença especial para usos não comerciais, o software é convertido em ferramenta para expressão e criação artística, deslocado de suas finalidades. Ferramentas deste tipo são comuns ao cotidiano de trabalho de FM, o que neste caso remete as ideias tratadas por Brennan e Resnick (2012) sobre o PC, por conectarem-se aqui, diferentes perspectivas da vida de FM a partir de um teor de questionamento por meio de tecnologias de seu trabalho. Chega-se, assim, na perspectiva de empoderamento político e tecnológico por parte do artista, uma vez que abrem-se as possibilidades de utilizar a computação para trabalhar com pautas que lhe são relevantes fora da esfera de trabalho.

\subsection{Controle Tóxico - LO e LR}

A partir da proposta de discutir jogos digitais, LO e LR, trazem os discursos de ódio presentes na cultura gamer (Figura 4). Em sua participação em comunidades de jogos, LR coletou conversas, comentários, debates alinhados à discursos homofóbicos, transfóbicos, machistas e misóginos (Figura 5). A obra busca problematizar esta cultura como tóxica, com pessoas dissidentes sendo constantemente atacadas. LR e LO pensaram em uma instalação para expor estes comentários que sufocam quem joga. A analogia com o sufocamento e a toxicidade é feita com a utilização de uma gosma (gel viscoso) onde um controle de videogame e alguns comentários estariam mergulhados.

A Figura 6 mostra o processo de impressão do controle utilizado na construção da instalação, sendo que LO e LR buscaram em repositórios abertos ${ }^{1}$ modelos tridimensionais de controles de videogame para a impressão. Este controle foi inserido como forma de discutir a constante vigilância (controle) normativa nestes espaços e a constante tentativa de dominação. Dessa forma, LO e LR buscam construir questionar (Brennan e Resnick, 2012) no sentido de repensar e deslocar os valores permeados nos mundos dos jogos, algo próximo à estratégia de iludir que Light (2011) apresenta.

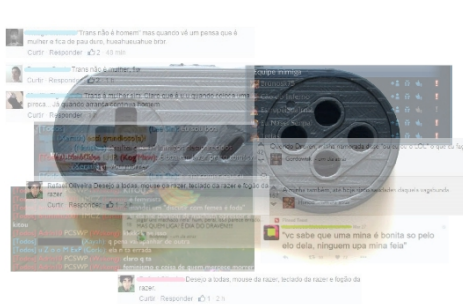

Figura 4. A concepção da instalação

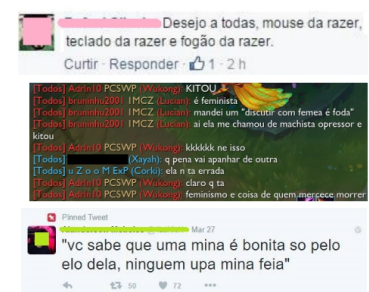

Figura 5. Conversas coletadas em fóruns de jogos.

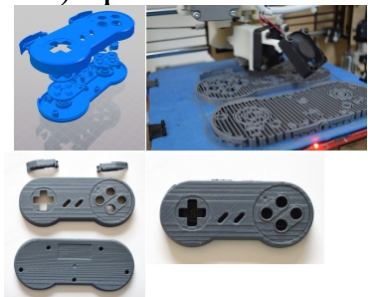

Figura 6. 0 processo de impressão 3D do controle.

Fazer experimentações para produzir os objetos necessários para a obra foi um desafio desde o princípio da produção e se consolidou com a utilização da tecnologia de impressão tridimensional. Ao se apropriarem de tecnologias e informações livres e abertas para a construção da obra, LO e LR se ligam aos valores Hacker e Maker (Levy, 1994), trazendo a importância do acesso e abertura de informações e tecnologias. Da mesma forma, a produção da gosma onde os elementos seriam misturados partiu de uma pesquisa sobre a produção de slime ou amoeba (existem muitas nomenclaturas para este tipo de material), uma brincadeira que segue a filosofia do "faça você mesmo/a" e da bricolagem e se popularizou na internet, contando com muito material disponível.

\footnotetext{
${ }^{1} \mathrm{O}$ modelo 3D se encontra em um repositório aberto https://www.thingiverse.com/thing:337896
} 
As discussões de Light (2011) sobre trapacear, remetem-se ao fato de que tecnologias e jogos possuem sistemas de códigos, regras que os regem. Consequentemente há limitações e brechas, o que abre espaço para exploração de falhas e para pensar desconstrução. Estas falhas não necessariamente dizem respeito a questões técnicas dos jogos, mas envolvem também construções socioculturais que estes fomentam e a interação que é construída entre as pessoas e o artefato. Ao trazerem o foco para as normatividades, LO e LR buscam fomentar questionamentos e expressão (Brennan e Resnick, 2012) sobre situações que experienciam. Neste processo de questionamento sobre a cultura dos jogos, discutem a construção de identidades, apontado por Light (2011) em obscurecer, uma vez que as tecnologias dos jogos se cruzam com outros espectros na construção identitária de quem joga.

\section{3.@oquetemarca - FHA e LO}

A obra resultado da colaboração entre FHA e LO discute as normatividades dos corpos, experimentando interação em redes sociais e mesclando virtualidade e presença física por meio da construção de redes de discussão e acolhimento. FHA e LO pretendiam valorizar o corpo enquanto algo individual e único, uma que é de cada pessoa e que não pode ser homogeneizado e essencializado. Nesta perspectiva são abordadas as marcas que fazem com que cada corpo seja único o que dentro de discursos normativos passam a ser alvo de ataque, negação e modificação estética e cirúrgica. Desta forma os artistas pensaram em uma instalação que segue a ideia exposta na Figura 3.

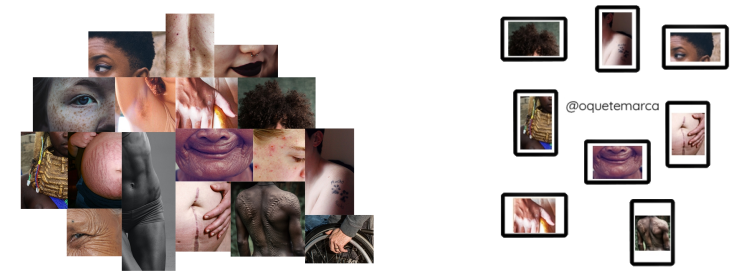

Figura 3: Imagens da obra @oquetemarca de FHA e LO Fontes: Composição dos autores (Oliveira, 2020) / Obra de FHA e LO

Assim, cada pessoa pode colaborar, enviando fotos para construir um banco de imagens exibidas em uma instalação de tablets. A ideia é construir uma rede para exercitar o deslocamento dos significados que são carregados pelos detalhes dos corpos, algo que reflete na construção de identidade. FHA e LO construíram expressão a partir do questionamento sobre o corpo nesta obra (Brennan e Resnick, 2012). A discussão de Light (2011) sobre obscurecer é percebida ao colocar na centralidade coisas que as pessoas em geral buscam esconder e das quais até mesmo sentem vergonha. A atitude de iludir remete a construção de novos significados a partir da interação que as pessoas constroem com a obra, dando espaço outro para as diferenças e alteridade. Ainda assim, a decisão sobre esconder ou mostrar coisas é de cada pessoa, em atitude que vai se ligar ao obscurecer, por remeter a construção de cada pessoa e sua identidade.

É interessante pontuar a problematização que a obra suscita ao ser construída em relação direta com redes sociais, tecnologias que ganharam espaço na cotidianidade e trazem influência às identidades e à visão que as pessoas têm de si mesmas e do mundo. Neste ponto, a conexão, discutida por Brennan e Resnick (2012), sobressai uma vez que quem interage com a obra acaba envolvido em uma rede que entrelaça as questões na qual a obra se apoia, além de inserir sua assinatura na coautoria da obra. Podem ser observadas discussões que remetem aos movimentos Hacker e Maker ao trazerem a 
possibilidade de ampla participação, defendendo a circulação livre da informação e das tecnologias e a descentralidade (Levy, 1994), afinal participação e envolvimento são abertos, fazendo com que os significados da obra sejam construídos a partir da interação.

\section{Considerações Finais}

A partir da base teórica da pesquisa buscou-se aprofundar as discussões sobre a construção de uma apropriação tecnológica significativa em comunidades que não estão amplamente presentes na computação. As discussões de Wing (2006), Nardelli (2019), André (2018), Brennan e Resnick (2012) trazem importantes marcos para compreender o PC, tendo sido um exercício desta pesquisa aproxima-las das discussões sobre a diversidade na computação. Entende-se diversidade, aqui, como pessoas dissidentes no que diz respeito ao gênero e sexualidade. Ainda assim, a partir da visão interseccional trazida pela Teoria Queer, não é possível endereçar e discutir estes aspectos de forma descolada no processo de construção de identidades, sendo necessário levar em consideração a complexidade do ser humano, da cultura e das relações de poder. A partir disso, percebe-se que as obras trazem temáticas diversas, passando por questões diretamente ligadas a movimentos LGBTTQIA+, como o caso da obra "Lar Doce Lar", mas também outras que envolvem o corpo, como no caso de "@oquetemarca", ou ainda as violências, como no caso de "Controle Tóxico".

Essas obras apontam a complexidade interdisciplinar pela qual se constrói a relação entre pessoas e tecnologias computacionais, discussão presente no campo CTS (Winner, 1986), e acabaram sendo também uma forma de ampliar as discussões e visões que são trazidas para refletir sobre o Pensamento Computacional. Compreender a maneira como estas relações se constroem é trivial para pensar em um processo de apropriação significativa, caminho que perpassa as discussões técnicas, sobre diversidade e sobre inclusão. A presente pesquisa se pautou em uma ação de extensão participativa e coletiva, tendo o envolvimento de diversas pessoas com suas pautas, habilidades e interesses. Dessa forma foi possível compreender que as relações entre as/os participantes e a tecnologia se desenvolve de maneira contextualizada, dada a partir de suas vivências para além dos encontros do grupo. Cada uma/um compreende e se apropria da tecnologia a sua maneira, em processos íntimos, mas ainda assim possíveis de compartilhamento com o coletivo. Dessa forma, nota-se a importância de abordagens participativas e coletivas como maneira de buscar por desconstrução, questionamento e democratização, em especial quando falamos em uma área com tanta dificuldades em envolver a diversidade em seus ambientes e culturas.

As discussões de Wing (2006), tópico (i), apontam que computação é um conjunto de múltiplas habilidades com diferentes níveis de abstração, o que é reforçado pela pesquisa aqui descrita. Também resgatamos os tópicos (v) e (vi) ao serem abordados problemas do cotidiano na comunicação e interação durante a ação da pesquisa, compreendendo que $\mathrm{PC}$ deve ser para todo mundo, integrado à vida e diretamente relacionado à pautas que são dadas pelas pessoas e não por artefatos ou algoritmos. Dessa forma, a pesquisa traz uma abordagem horizontalizada como forma de trabalhar a apropriação tecnológica e o PC por meio de expressão, conexão e questionamento (Brennan e Resnick, 2012), ao tempo em que se relaciona com o design para obliquidade de Light (2011), como forma de compreender a potencialidade ética e política da computação na vida das pessoas e, em especial, para grupos da diversidade. 


\section{Agradecimentos}

O presente trabalho foi realizado com apoio da Coordenação de Aperfeiçoamento de Pessoal de Nível Superior - Brasil (CAPES) - Código de Financiamento 001.

\section{Referências}

ABGLT - Associação Brasileira de Lésbicas, Gays, Bissexuais, Travestis e Transexuais (2016) "Pesquisa Nacional sobre o Ambiente Educacional no Brasil 2015: as experiências de adolescentes e jovens lésbicas, gays, bissexuais, travestis e transexuais em nossos ambientes educacionais". Secretaria de Educação de Curitiba: ABGLT.

Amaral, Marília Abrahão; Emer, Maria Claudia Figueiredo Pereira; Bim, Silvia Amélia; Setti, Mariangela Gomes; Gonçalves, Marcelo Mikosz. (2017) "Investigando questões de gênero em um curso da área de Computação". Revista Estudos Feministas, v. 25, e. 2, p. 857-874. DOI: <https://dx.doi.org/10.1590/18069584.2017v25n2p857>.

Ames, Morgan G.; Lindtner, Silvia; Bardzell, Shaowen; Bardzell, Jeffrey; Ngyen, Lilly; Ahmed, Syed I.; Jahan, Nusrat; Jackson, Steven J.; e Dourish, Paul. (2018) "Making or Making Do? Challenging the mythologies of making and hacking". Journal of Peer Production. Ed. 12. Disponível em: http://peerproduction.net/issues/issue-12Makerspaces-and-institutions/varia-2/making-or-making-do/. Acessado em: 03/04/2019.

André, Claudio F. (2018) "O pensamento computacional como estratégia de aprendizagem, autoria digital e construção da cidadania". In: teccogs - Revista Digital de Tecnologias Cognitivas, n. 18, p. 94-109.

Bardin, Laurence. (2011) “Análise de Conteúdo”. São Paulo: Edições 70.

Bardzell, Jeffrey e Bardzell, Shaowen. (2015) "Humanistic HCI”. Synthesis Lectures on Human-Centered Informatics, vol. 8, no. 4, pp. 1-185.

Bilimoria, Diana e Stewart, Abigail J.. (2009) “'Don't Ask, Don't Tell”: The Academic Climate for Lesbian, Gay, Bisexual, and Transgender Faculty in Science and Engineering”. NWSA Journal, v. 21, e. 2, pp. 85-103.

Blikstein, P. (2008) "O pensamento computacional e a reinvenção do computador na educação" [recurso eletrônico]. Acesso em 10 jul. 2019. Disponível em www.blikstein.com/paulo/documents/online/ol_pensamento_computacional.html.

Blikstein, P., e Worsley, M. A. B. (2016) "Children Are Not Hackers: Building a Culture of Powerful Ideas, Deep Learning, and Equity in the Maker Movement". In: Peppler, K.; Halverson, E; Kafai, Y. B. (eds.). Makeology, ed 1, v, 1. Routledge.

Bødker, Susanne. (2015) "Third-Wave HCI, 10 Years Later - Participation and Sharing". Revista Interactions, v. 22 ed. 5. P. 24-31. Acesso em: $<$ https://dl.acm.org/citation.cfm?id=2804405>.

Brandão, Carlos Rodrigues e Borges, Maristela Correa. (2007) “A pesquisa participante: um momento da educação popular”. Rev. Ed. Popular, v. 6. p. 51-62.

Breslin, Samantha e Wadhwa, Bimlesh. (2014) "Exploring Nunanced Gender Perspectives within the HCI Community". In: Proceedings of the India HCI 2014 
Conference on Human Computer Interaction (IndiaHCI '14). Association for Computing Machinery, New York, NY, USA, p. 45-54. DOI:https://doi.org/10.1145/2676702.2676709

Breslin, Samantha e Wadhwa, Bimlesh. (2015) “Towards a Gender HCI Curriculum". In: Proceedings of the 33rd Annual ACM Conference Extended Abstracts on Human Factors in Computing Systems (CHI EA '15). Association for Computing Machinery, New York, NY, USA, p. 1091-1096. DOI: https://doi.org/10.1145/2702613.2732923.

Butler, Judith. (2007) "Corpos que pesam: sobre os limites discursivos do "sexo"”. In: Louro, Guacira Lopes. O corpo educado: pedagogias da sexualidade. Belo Horizonte: Autêntica, p. 153-172.

Butler, Judith. (2009) "Performatividad, Preccariedad y Políticas Sexuales". Revista de Antropología Iberoamericana, Madri, v.4, n.3, , p. 321-226. Disponível em: http://www.aibr.org/antropologia/04v03/criticos/040301b.pdf. Acesso em: 10/09/2016.

Butler, Judith. (2017) "Problemas de gênero: feminismo e subversão da identidade". 13 ed. Tradução de Renato Aguiar. Rio de janeiro: Civilização Brasileira.

Castelini, Pricila. (2018) "Mulheres na computação: percepções, memórias e participação de estudantes e egressas". Dissertação (Mestrado em Tecnologia e Sociedade) - Universidade Tecnológica Federal do Paraná, Curitiba. Disponível em http://repositorio.utfpr.edu.br/jspui/handle/1/2944.

Cech, Erin A. e Waidzunas, Tom J. (2011) "Navigating the heteronormativity of engineering: the experiences of lesbian, gay, and bisexual students. Engineering Studies", V. 3 E. $1, \quad$ p. $1-24, \quad 2011 . \quad$ DOI: https://doi.org/10.1080/19378629.2010.545065.

Evangelista, Rafael. (2014) "O movimento software livre do Brasil: política, trabalho e hacking". Horizontes Antropológicos, Porto Alegre, v. 20, n. 41, p. 173-200. DOI http://dx.doi.org/10.1590/S0104-71832014000100007.

Fonseca, Felipe Schmidt. (2014) "REDELABS: Laboratórios experimentais em rede". Dissertação de Mestrado em Divulgação Científica e Cultural - Instituto de Estudos da Linguagem, Universidade Estadual de Campinas (UNICAMP), Campinas.

Francisco, Deise Juliana; Azevêdo, Edjane Mikaelly Silva; Ferreira, Adilson Rocha Ferreira; e Caitano, Alexandre Rodrigues. (2021) "Análise de Conteúdo: como podemos analisar dados no campo da educação e tecnologias". In: Pimentel, Mariano; Santos, Edméa. (Org.) "Metodologia de pesquisa científica em Informática na Educação: abordagem qualitativa". Porto Alegre: SBC, 2021. (Série Metodologia de Pesquisa em Informática na Educação, v. 3) Disponível em: $<$ https://metodologia.ceie-br.org/livro-3/>

Freire, Paulo. (2015) “Extensão ou Comunicação?” Tradução de Rosiska Darcy de Oliveira. São Paulo: Editora Paz e Terra, ed 17.

Grogan, Abi. (2014) "“It's never good to carry a secret..." Findings of the E\&T magazine lesbian, gay, bisexual and transgender (LGBT) survey". Engineering \& Technology, V. 9, E. 7, p. 40-42. Ago. DOI: http://dx.doi.org/10.1049/et.2014.0726. 
Himanen, Pekka. (2003) "La ética del Hacker y el espíritu de la era de la información”. Barcelona: Destino.

Levy, Steven. (1994) "Hackers: heroes of the computer revolution". Nova Iorque: Dell Publishing. ISBN 0-385-31210-5.

Light, Ann. (2011) "HCI as Heterodoxy: Technologies of identity and the Queering of interaction with computers". Revista Interacting with Computers, v. 23, ed. 5. P. 430438. DOI: https://doi.org/10.1016/j.intcom.2011.02.002.

Louro, Guacira Lopes. (2016) "Um Corpo Estranho - Ensaios sobre sexualidade e Teoria Queer". 2ed. Belo Horizonte: Autêntica.

Marconi, Marina de Andrade e Lakatos, Eva Maria. (2003) "Fundamentos de Metodologia Científica". $5^{\text {a }}$ ed. São Paulo: Atlas.

Marshall, Andrea e Rode, Jennifer A. (2018) "Deconstructing Sociotechnical Identity in Maker Cultures". In: Proceedings of $4^{\text {th }}$ Gender\&IT conference, Heilbronn, Germany (GenderIT'18). ACM, New York, NY, USA, 10 pages. https://doi.org/10.1145/3196839.3196855

Merkle, Luiz Ernesto. (2010) "A História da Informatização como Desafio à Teoria em Computação". In: Anais do VIII Congresso Iberoamericano de Ciência, Tecnologia e Gênero. Disponível em http://files.dirppg.ct.utfpr.edu.br/ppgte/eventos/cictg/conteudo_cd/E13_A_História_d a_Informatização.pdf. Acesso em: 23/05/2018.

Mills, C. Wright. (2009) "Sobre o Artesanato Intelectual”. In: Mills, C. Wright. "Sobre o Artesanato Intelectual e Outros Ensaios". Rio de Janeiro: Jorge Zahar, ed. 1, p. 2158 .

Miskolci, Richard. (2014) "Estranhando as Ciências Sociais: Notas Introdutórias sobre Teoria Queer". Revista Florestan, ano 1, n. 2. Dispinível em: http://www.revistaflorestan.ufscar.br/index.php/Florestan/article/view/62/pdf_23. Acesso em: 06/05/2018.

Nardelli, Enrico. (2019) "Do we really need computational thinking?" Revista Communications of the ACM, v. 62, ed. 2. p. 32-35.

Oliveira, Leander Cordeiro de e Costa, Tácio Hugo Gouveia. (2021) "Descrição da obra 'Sem Título' de Ugo Vêa”. Cadernos de Gênero e Tecnologia, Curitiba, v. 14, n. 43, p. 220-228, jan.jun. 2021. Acesso em https://periodicos.utfpr.edu.br/cgt/article/view/12429

Oliveira, Leander Cordeiro de. (2020) "Nós somos gente... gente computada igual a você': a construção de um estranhamento do computar'. Tese de Doutorado em Tecnologia e Sociedade. Universidade Tecnológica Federal do Paraná, Curitiba. Acesso em http://repositorio.utfpr.edu.br/jspui/handle/1/5072

Preciado, Paul Beatriz. (2011) "Multidões Queer: notas para uma política dos 'anormais"”. Estudos Feministas, Florianópolis, vol. 19(1), n. 312, p. 11-20.

Preciado, Paul Beatriz. (2014) "Manifesto Contrasexual”. Tradução de Maria Paula Gurgel Ribeiro. São Paulo: n-1 edições. 
Rode, Jennifer A.. (2011) "A Theoretical Agenda for Feminist HCI". Interact. Comput. 23, 5, 393-400. http://dx.doi.org/10.1016/j.intcom.2011.04.005

Sierra, Jamil C. (2017) "Que quer o Queer? Sobre o contexto de emergência e suas contribuições aos deslocamentos pós-identitários”. In: Fonseca, A. C. M.; Galantin, D. V.; Ribas, T. F. (orgs). Políticas não identitárias. São Paulo: Intermeios, p. 137 160.

Silva, Jane Reolo da. (2016a) "Educação, tecnologias e gênero: uma reflexão sobre o androcentrismo na tecnologia”. Dissertação de Mestrado em Educação: Currículo Programa de Estudos Pós-Graduados em Educação: Currículo, Pontifícia Universidade Católica de São Paulo, São Paulo.

Silva, Jane Reolo da. (2016b) "O Androcentrismo Tecnológico e o Empoderamento Feminino". In: Anais do FabLearn Brazil, São Paulo.

Silva, Rodrigo Barbosa e. (2017) "Para Além do Movimento Maker: Um contraste de diferentes tendências em espaços de construção digital na Educação". Tese de Doutorado em Tecnologia e Sociedade - Pós-Graduação em Tecnologia e Sociedade, Universidade Tecnológica Federal do Paraná (UTFPR), Curitiba.

Spargo, Tamsim. (2006) “Foucault e a Teoria Queer”. Rio de Janeiro: Pazulin. Juiz de Fora: Editora UFJF.

Stout, J. G. e Wright H. M. (2016) "Lesbian, Gay, Bisexual, Transgender, and Queer Students' Sense of Belonging in Computing: An Intersectional Approach". Revista IEEE Computing in Science \& Engineering.

Trenshaw, K. F.; Hetrick, A; Oswald, R. F.; Vostral, S. L.; Loui, M. C. (2013) "Lesbian, Gay, Bisexual, and Transgender Students in Engineering: Climate and Perceptions". IEEE Frontiers in Education Conference (FIE), Oklahoma City, p. 1238-1240.

Wing, J. M. (2006) "Computational thinking”. Revista Communications of the ACM, v. 49 , ed. 3. p. 33-36.

Winner, Langdon. (1986) "Do Artifacts have Politics?" In: . "The Whale and the Reactor - A Search for Limits in an Age of High Technology". Chicago: The University of Chicago Press. p. 19-39. 